\title{
An Electronic Adherence Measurement Intervention to Reduce Clinical Inertia in the Treatment of Uncontrolled Hypertension: The MATCH Cluster Randomized Clinical Trial
}

\author{
Ian M. Kronish, M.D., M.P.H. ${ }^{\text {, }}$ Nathalie Moise, M.D. ${ }^{\text {, }, ~ T h o m a s ~ M c G i n n, ~ M . D ., ~ M . P . H . ~}{ }^{2}$, Yan Quan, M.A. ${ }^{\text {', }}$ \\ William Chaplin, Ph.D. ${ }^{3}$, Benjamin D. Gallagher, M.D. ${ }^{7}$, and Karina W. Davidson, Ph.D. ${ }^{1}$ \\ ${ }^{1}$ Center for Behavioral Cardiovascular Health, Columbia University Medical Center, New York, NY, USA; ${ }^{2}$ Department of Medicine, Hofstra North \\ Shore-LIJ School of Medicine, Manhasset, NY, USA; ${ }^{3}$ Department of Psychology, St. John's University, Jamaica, NY, USA.
}

BACKGROUND: To appropriately manage uncontrolled hypertension, clinicians must decide whether blood pressure (BP) is above goal due to a need for additional medication or to medication nonadherence. Yet, clinicians are poor judges of adherence, and uncertainty about adherence may promote inertia with respect to medication modification.

OBJECTIVE: We aimed to determine the effect of sharing electronically-measured adherence data with clinicians on the management of uncontrolled hypertension.

DESIGN: This was a cluster randomized trial.

PARTICIPANTS: Twenty-four primary care providers (12 intervention, 12 usual care; cluster units) and 100 patients with uncontrolled hypertension (65 intervention, 35 usual care) were included in the study.

INTERVENTIONS: At one visit per patient, clinicians in the intervention group received a report summarizing electronically measured adherence to the BP regimen and recommended clinical actions. Clinicians in the control group did not receive a report.

MAIN MEASURES: The primary outcome was the proportion of visits with appropriate clinical management (i.e., treatment intensification among adherent patients and adherence counseling among nonadherent patients). Secondary outcomes included patient-rated quality of care and communication during the visit.

KEY RESULTS: The proportion of visits with appropriate clinical management was higher in the intervention group than the control group (45 out of $65 ; 69 \%$ ) versus (12 out of $35 ; 34 \% ; p=0.001)$. A higher proportion of adherent patients in the intervention group had their regimen intensified $(p=0.01)$, and a higher proportion of nonadherent patients in the intervention group received adherence counseling $(p=0.005)$. Patients in the intervention group were more likely to give their clinician high ratings on quality of care $(p=0.05)$, and on measures of patientcentered $(p=0.001)$ and collaborative communication $(p=0.02)$.

Electronic supplementary material The online version of this article (doi:10.1007/s11606-016-3757-4) contains supplementary material, which is available to authorized users.

Received August 25, 2015

Revised February 9, 2016

Accepted May 10, 2016

Published online June 2, 2016
CONCLUSIONS: Providing clinicians with electronicallymeasured antihypertensive adherence reports reduces inertia in the management of uncontrolled hypertension. TRIAL REGISTRATION: NCT01257347; http://clinicaltrials.gov/show/NCT01257347

KEY WORDS: uncontrolled hypertension; medication adherence; clinical inertia; randomized clinical trial.

J Gen Intern Med 31(11): 1294-300

DOI: $10.1007 / \mathrm{s} 11606-016-3757-4$

(c) Society of General Internal Medicine 2016

\section{INTRODUCTION}

Hypertension is the most common chronic illness in developed countries, affecting approximately $30 \%$ of U.S. adults. ${ }^{1,2}$ Despite strong evidence that controlling hypertension improves cardiovascular outcomes and lowers health care costs, ${ }^{3-5}$ one in three patients prescribed medications for hypertension are not reaching guideline-recommended blood pressure (BP) goals. ${ }^{6}$ Thus, improving BP control remains a major unmet public health goal. ${ }^{7,8}$

Two major reasons for uncontrolled hypertension are medication nonadherence ${ }^{9-11}$ and clinical inertia-defined here as a lack of treatment intensification despite an elevated BP. ${ }^{12-16}$ At least one-third of patients do not adhere to their antihypertensive regimen. ${ }^{17,18}$ Accordingly, experts recommend assessing medication adherence prior to intensifying treatment. ${ }^{19-21}$ Yet clinicians are poor at accurately identifying nonadherence and are often uncertain about the true level of adherence. ${ }^{22,23}$ Uncertainty may foster the "wait until next visit" approach that commonly underlies clinical inertia. ${ }^{13}$

Electronic monitoring is commonly regarded as the best available measure of day-to-day medication adherence. $^{24,25}$ Electronic monitoring is less vulnerable to recall bias and over-reporting than patient-reported adherence measures. ${ }^{26}$ Electronic monitoring also provides objective information on the extent of adherence immediately prior to BP measurement, and hence has the potential to maximally inform management decisions for uncontrolled hypertension. ${ }^{27}$ 
Accordingly, we designed a cluster randomized trial to determine whether providing clinicians with electronically measured adherence data in conjunction with clinical decision support could improve the management of uncontrolled hypertension. The goal was to directly assess the impact of the receipt of such a report on hypertension management during a single patient visit. Clustering was performed at the clinician level to prevent spillover effects from exposure to the adherence feedback intervention among clinicians in the control arm. By prompting increased consideration of adherence in management decisions and reducing uncertainty about adherence, we hypothesized that providing clinicians with electronic adherence data would lead to reduced clinical inertia. Secondary goals were to determine the effect of the intervention on patient-clinician communication and patient satisfaction with hypertension care.

\section{METHODS}

\section{Design and Setting}

The design was a two-arm, parallel-group, cluster randomized clinical trial conducted at two hospital-based primary care practices in New York City from 2010 to 2014. Both practices serve racially and ethnically diverse patient populations from underserved communities. Primary care providers comprised the clusters.

\section{Participants}

Primary care providers were eligible if they had completed clinical training and maintained a continuity practice at one of the two sites. They also had to have at least one encounter with an eligible patient.

Patients were eligible for a run-in if they had an established diagnosis of hypertension; were prescribed at least one BP medication; had at least two consecutive clinic visits with elevated BP according to JNC-7 guidelines (i.e., $\mathrm{BP} \geq 140 / 90$ $\mathrm{mmHg}$ or $\geq 130 / 80 \mathrm{mmHg}$ if diabetes or chronic kidney disease $)^{28}$; were 18 to 80 years old; and had at least one prior visit with a clinician enrolled in the study. Patients were excluded if they had severe mental illness; resided in a long-term care facility; were unable to use the electronic adherence device due to physical or cognitive impairment; were non-English or non-Spanish speaking; or were unavailable for follow-up. Research assistants confirmed initial eligibility by measuring BP using a standard protocol recommended by the American Heart Association and a BP Tru automatic sphygmomanometer (BP Tru Medical Devices; Coquitlam, Canada). ${ }^{29}$ Final patient eligibility was assessed at the next scheduled clinic visit. Patients were eligible if they continued to have elevated $\mathrm{BP}$ at this visit. Patients were excluded if electronic adherence data were unavailable at the visit. Institutional Review Boards of the Icahn School of Medicine at Mount Sinai and Columbia University Medical Center approved the protocol. All clinicians and patients provided informed consent.

\section{Baseline Assessments}

At enrollment, clinicians completed a questionnaire that assessed demographic characteristics and years in practice. At enrollment, patients completed an interview assessing demographic characteristics. Medical problems and medications were abstracted from the electronic medical record. Charlson score was computed based on patients' medical problem list. ${ }^{30}$

\section{Medication Adherence}

Medication adherence was assessed using the fourcompartment MedSignals® pillbox (VitalSignals Inc., Lexington, KY). The device records the date and time when each compartment is opened. Adherence data are transmitted from the pillbox to the MedSignals server via landline or, for devices used in the final year of the study, via a cell phone in the device. Patients were instructed to fill the pillbox with their antihypertensive medications. The device's reminder system was disabled. Adherence to each BP medication was calculated as the percent of doses taken as prescribed. Extra doses were excluded from adherence calculations. Days on which patients were hospitalized or had been instructed by their clinician to stop taking a monitored medication were also excluded. Overall regimen adherence was calculated as the mean adherence to all monitored BP medications. As per convention and expert opinion, patients were categorized as nonadherent if adherence was less than $80 \%{ }^{26}$

\section{Randomization and Allocation Concealment}

Providers were block randomized in a 1:1 ratio to the intervention or control group. Randomization was generated by a computerized random number sequence. Provider assignments were known only to a third party who had no role in outcome assessments. Randomization was stratified by recruitment site. Patients were analyzed in the group to which their provider was randomized. To assess blinding, research assistants guessed which group patients had been assigned to after completing outcome assessments.

\section{Intervention}

The intervention occurred at the clinician cluster level. At the time of clinician enrollment, clinicians in the intervention group received a brief, one-time training $(<10$ minutes) in how to interpret the adherence report. Subsequently, these clinicians were provided with a one-time adherence report immediately prior to a visit with eligible patients. The onepage report (Appendix Figure 1) displayed the percent adherence to each BP medication and to the overall regimen for the entire monitoring period and the 7 days preceding the intervention visit. The report also provided clinical decision support by listing "suggested clinical actions" according to adherence status. However, the actions taken were at clinicians' discretion. Patients assigned to the intervention group were informed their adherence was recorded by the electronic 
pillbox and might be shared with their clinician depending on randomization, but did not receive adherence counseling by study personnel.

\section{Usual Care}

Clinicians randomized to the control group did not receive an adherence report and were expected to manage their patients according to usual care. Like patients in the intervention group, patients in the control group were informed their adherence was recorded and might be shared with their clinician depending on randomization. No adherence counseling was provided. As neither providers nor patients in the control group had access to adherence data, the potential for contamination was reduced.

\section{Outcomes}

The primary outcome was appropriateness of management of uncontrolled hypertension at visits with adherence report feedback versus usual care. Appropriateness depended on adherence status. In adherent patients (regimen adherence during the 7 days prior to intervention visit $\geq 80 \%$ ), management was categorized as appropriate if providers intensified the regimen, ordered testing for identifiable causes of hypertension, or referred patients to a hypertension specialist. In nonadherent patients (regimen adherence during entire monitoring period < $80 \%$ ), management was categorized as appropriate if providers conducted adherence counseling or simplified the regimen to facilitate adherence. Adherence counseling was defined as any documentation of assessing, arranging, assisting, or advising patients about adherence to their BP medications. For patients who were nonadherent over the entire monitoring period but adherent in the week prior to the intervention visit, management was defined as appropriate if providers conducted adherence counseling and took action to intensify treatment. Two medically trained study personnel blinded to group assignment independently abstracted data pertaining to outcome assessments from medical records after a third person had reviewed records to redact wording that could reveal group assignment. Differences in categorization were resolved through consensus.

Secondary outcomes included patient ratings of the quality of care during the visit ("poor," "fair," "good," "very good," "excellent"); satisfaction with the amount of time spent during the visit ("too little," "too much," "just right"); and perceptions of patient-centered and collaborative communication. Collaborative communication was assessed using a four-item questionnaire adapted from the Patient Assessment of Chronic Illness scale. ${ }^{31,32}$ Patient-centered communication was assessed by adapting a four-item questionnaire assessing communication around antidepressants. ${ }^{33}$ For both questionnaires, response options for individual items ranged from 0 ("not at all") to 3 ("very much"), and items were summed such that scores $\geq 8$ indicated collaborative or patient-centered communication, respectively. Patient-rated outcomes were assessed by interviewing patients immediately after clinician visits.

\section{Process Evaluation}

Patients were asked about the ease of using the electronic pillbox using a five-item Likert scale ("very hard" to "very easy"). They were also asked whether they would be willing to use the pillbox again if asked by their clinicians.

\section{Statistical Analysis}

The kappa statistic was used to assess agreement between outcome assessors' guesses about group assignment. Generalized estimating equation (GEE) models (logit link) fitted with clinician as the cluster variable, appropriateness of hypertension management as the outcome, and intervention group as the explanatory variable were used to assess the effect of the intervention on outcomes. Post-hoc sensitivity analyses were conducted in which the sample was restricted to patients who met JNC-8 criteria for uncontrolled hypertension (BP $\geq 140 / 90$ $\mathrm{mmHg}$ irrespective of diabetes or chronic kidney disease status), ${ }^{34}$ as these guidelines were released during the final year of recruitment. A GEE model was also used to estimate the intraclass correlation coefficient (ICC) for appropriateness of management at the clinician level.

\section{Sample Size}

Sample size was calculated to have sufficient power to detect meaningful differences in appropriateness of hypertension management between intervention and control groups. Each patient-clinician encounter was treated as independent and the sample size was inflated to account for the design effect (DE) of clustering of patients within clinician where $\mathrm{DE}=1+$ (number of patients per cluster -1$) *$ intra-class correlation coefficient (ICC). ${ }^{35,36}$ Average cluster size was estimated at seven patients per provider. We estimated a small ICC $(0.01) .{ }^{35-38}$ The sample size calculation was performed with a significance level of 0.05 and $80 \%$ power. Based on prior studies showing clinical inertia in $60 \%$ of hypertension visits, ${ }^{35-41}$ we estimated needing a sample of 200 patient-clinician visits to detect a $33 \%$ improvement in visits with appropriate management. We included a stopping rule in which recruitment would be stopped at the midpoint for futility if the $\mathrm{z}$-score was negative or for efficacy if the z-score was positive and the $p$ value $\leq 0.001 .^{42,43}$ As we met the efficacy stopping rule, enrollment stopped after 100 patients. All patient-clinician encounters were analyzed according to the group they were randomly assigned. SPSS (version 22.0, IBM Corp., Armonk, NY) was used for all analyses.

\section{RESULTS Participant Characteristics}

We enrolled 49 primary care providers. No providers declined participation. Twenty-four providers (12 intervention, 12 control) had at least one visit at which the adherence report was 
available (Fig. 1). Characteristics of providers in the intervention and control groups were similar. (Table 1).

We screened 497 patients, and consented 200 for the run-in. Forty-three patients $(9 \%)$ declined participation at the screening visit and 254 patients (51\%) were ineligible, primarily due to controlled BP $(n=92)$, unavailability for follow-up $(n=27)$, severe mental illness $(n=17)$, and cognitive impairment $(n=16)$. Of the 200 patients who consented to the electronic monitoring run-in, 100 had adherence reports available at the follow-up visit and were eligible for the trial. Reasons for ineligibility after the run-in included controlled BP $(n=37)$, no pillbox data $(n=24)$, adherence report not provided to clinician on time $(n=15)$; other reasons $(n=9)$; declined follow-up $(n=9)$; lost to follow-up $(n=5)$; and deceased $(n=1)$.

Due to chance, alone, 65 patients belonged to providers in the intervention group and 35 to providers in the control group. Characteristics of patients in each group were similar (Table 2). Patients were representative of their clinic populations with mean age of 64 years, $72 \%$ women, $75 \%$ Hispanic, $54 \%$ having a less than high school education, and $83 \%$ having Medicaid or self-pay health insurance status. The mean $\mathrm{BP}$ at the time of the intervention was $155 / 83 \mathrm{mmHg}$, and $56 \%$ of patients were prescribed $\geq 3$ BP medications. Medication adherence was measured for a mean of $52 \pm 32$ days. Forty-one percent of patients were nonadherent $(<80 \%$ of prescribed doses); three of these patients were adherent in the week before the intervention visit. The majority of patients (64\%) found the electronic pillbox "very easy" to use, and almost all (94\%) said they would use it again if asked.

\section{Outcomes}

A greater proportion of patients assigned to the intervention group received appropriate management of uncontrolled hypertension than patients assigned to the control group (69\% versus $34 \% ; p=0.001$; Table 3 ). A sensitivity analysis restricting the sample to patients with $\mathrm{BP} \geq 140 / 90 \mathrm{mmHg}(N=87)$ showed similar results (70 \% of intervention patients versus $40 \%$ of control patients; $p=0.007)$. The ICC for appropriateness of management was 0.06 . Outcome assessors' guessed group assignment correctly $56 \%$ of the time (kappa 0.02, $p=0.72$ ).

A greater proportion of adherent patients had their BP regimen intensified if they were in the intervention group compared to the control group (56\% versus $26 \%$; $p=0.01$ ). There were no differences in the proportions of adherent patients that were ordered tests for identifiable hypertension or were referred to hypertension specialists. A greater proportion of nonadherent patients received adherence counseling if they were in the intervention group compared to the control group (84\% versus $39 \%, p=0.005)$. There was no difference in the proportion of nonadherent patients that had their BP regimen simplified.

Patients assigned to the intervention were more likely to give their providers high ratings on quality of care during the visit $(p=0.05)$, patient-centered $(p=0.001)$, and collaborative communication about hypertension $(p=0.02)$ (Table 4$)$. There was also a trend toward intervention patients being more likely to rate the amount of time spent during the visit as "just right" (92\% versus $80 \%, p=0.11$ ).

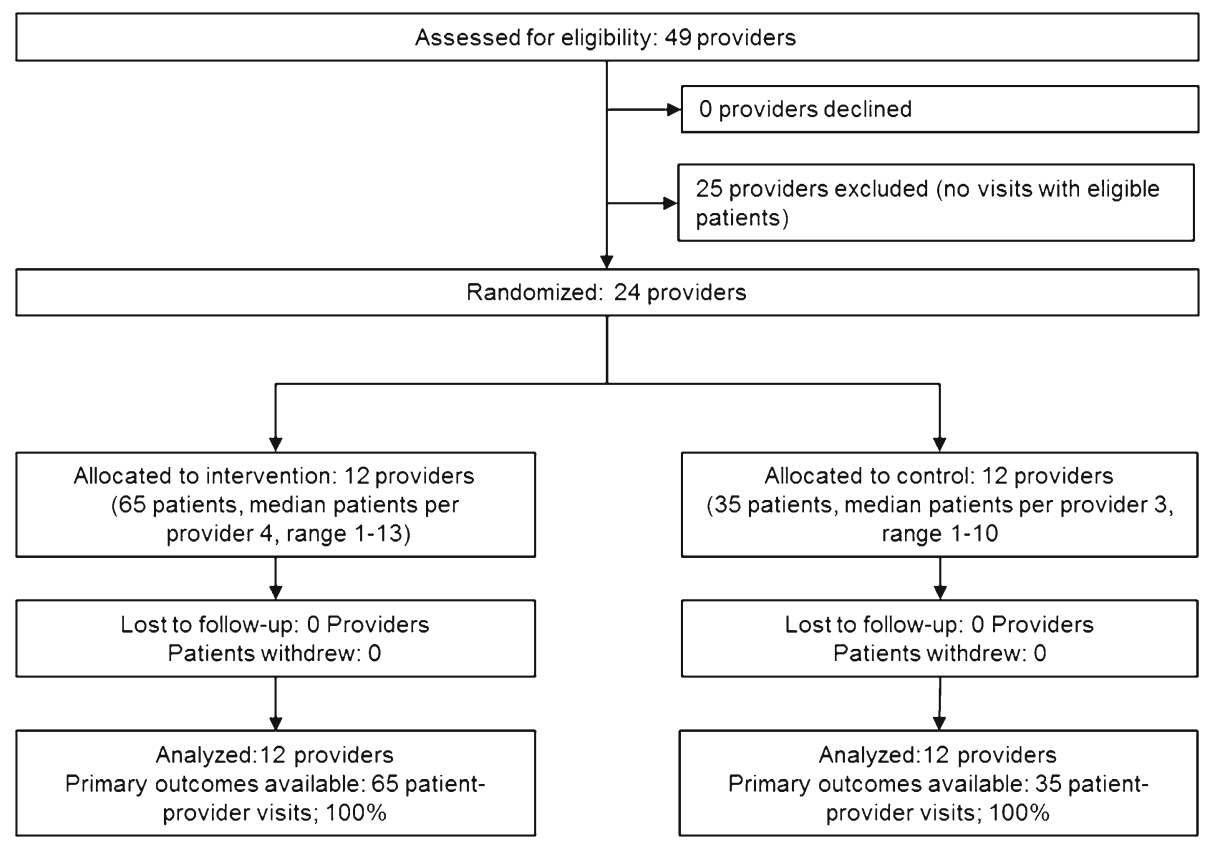

Figure 1. CONSORT (Consolidated Standards of Reporting Trials) extension for cluster randomized trials flow diagram of the measuring adherence to control hypertension (MATCH) Trial*. 
Table 1. Clinician Characteristics According to Group Assignment in the Measuring Adherence to Control Hypertension (MATCH) Trial

\begin{tabular}{lll}
\hline \hline $\begin{array}{l}\text { Clinician } \\
\text { characteristics }\end{array}$ & $\begin{array}{l}\text { Electronic adherence } \\
\text { intervention }(\boldsymbol{N = 1 2})\end{array}$ & $\begin{array}{l}\text { Usual care } \\
\text { control }(\boldsymbol{N = 1 2})\end{array}$ \\
\hline $\begin{array}{l}\text { Age in years, mean } \\
\text { (SD) }\end{array}$ & $46(11)$ & $48(10)$ \\
$\begin{array}{l}\text { Female } \\
\text { Hispanic }\end{array}$ & $7(58)$ & $6(50)$ \\
$\begin{array}{l}\text { White } \\
\text { Years in practice, } \\
\text { mean (SD) }\end{array}$ & $9(9)$ & $3(25)$ \\
& $15(12)$ & $10(83)$ \\
\hline
\end{tabular}

Data are presented as $N(\%)$ unless otherwise specified

\section{CONCLUSIONS}

We found that providing electronically measured adherence data plus clinical decision support to clinicians at the time of primary care visits substantially improved clinician management of uncontrolled hypertension. The receipt of adherence reports increased regimen intensification in adherent patients and increased medication adherence counseling in nonadherent patients. Sharing objectively measured adherence data also improved patient ratings of quality of care and clinician communication. These results provide evidence in support of a measurement-guided medication management approach to treating patients with uncontrolled hypertension. ${ }^{27}$

Table 2. Patient Characteristics According to Group Assignment in the Measuring Adherence to Control Hypertension (MATCH) Trial

\begin{tabular}{|c|c|c|}
\hline Patient characteristics & $\begin{array}{l}\text { Electronic adherence } \\
\text { intervention }(N=65)\end{array}$ & $\begin{array}{l}\text { Usual care } \\
\text { control } \\
(N=35)\end{array}$ \\
\hline Age in years, mean (SD) & $64(9)$ & $64(8)$ \\
\hline Female & 50 (77) & $22(63)$ \\
\hline Hispanic & $47(72)$ & $28(80)$ \\
\hline Born outside United States* & $46(71)$ & $29(83)$ \\
\hline Non-White & $42(71)$ & $24(75)$ \\
\hline $\begin{array}{l}\text { Less than high school } \\
\text { education }\end{array}$ & $35(55)$ & $17(49)$ \\
\hline Medicaid or self-pay & $55(85)$ & $28(80)$ \\
\hline Lives alone & $53(82)$ & $25(71)$ \\
\hline $\begin{array}{l}\text { Years with provider, median } \\
\text { (IQR) }\end{array}$ & $4(7)$ & $5(13)$ \\
\hline Diabetes & $37(57)$ & $26(74)$ \\
\hline $\begin{array}{l}\text { Chronic kidney disease } \\
(\text { GFR < 60) }\end{array}$ & $20(31)$ & $10(29)$ \\
\hline $\begin{array}{l}\text { Charlson Comorbidity } \\
\text { Index, mean (SD) }\end{array}$ & $2.8(2.1)$ & $2.9(1.8)$ \\
\hline $\begin{array}{l}\text { Number of medical } \\
\text { problems addressed during } \\
\text { visit, mean (SD) }\end{array}$ & $5.4(2.5)$ & $4.9(2.1)$ \\
\hline $\begin{array}{l}\text { Systolic BP, mean (SD), mm } \\
\mathrm{Hg}\end{array}$ & $156(17)$ & $154(16)$ \\
\hline $\begin{array}{l}\text { Diastolic BP, mean (SD), } \\
\mathrm{mm} \mathrm{Hg}\end{array}$ & $83(13)$ & $83(13)$ \\
\hline $\begin{array}{l}\text { Prescribed } 3 \text { or more BP } \\
\text { medications }\end{array}$ & $34(52)$ & $22(63)$ \\
\hline $\begin{array}{l}\text { Nonadherent }(<80 \%) \text { to BP } \\
\text { regimen }\end{array}$ & $27(42)$ & $14(40)$ \\
\hline
\end{tabular}

Data are presented as $N$ (\%) unless otherwise specified. Data are missing from two or fewer participants for all measures except Charlson for which data are missing on nine participants

* Patients born in Puerto Rico were categorized as born outside the United States

IQR interquartile range; PHQ 8-item Patient Health Questionnaire; BP blood pressure
Table 3. Comparison of Clinician Management According to Study Arm in the Measuring Adherence to Control Hypertension (MATCH) Trial

\begin{tabular}{|c|c|c|c|}
\hline Outcome measure & $\begin{array}{l}\text { Electronic } \\
\text { adherence } \\
\text { intervention }\end{array}$ & $\begin{array}{l}\text { Usual } \\
\text { care } \\
\text { control }\end{array}$ & $\begin{array}{l}p \\
\text { value }\end{array}$ \\
\hline $\begin{array}{l}\text { Among patients adherent } \\
\text { in week prior to outcome } \\
\text { visit, only }\end{array}$ & $N=34$ & $N=19$ & \\
\hline Intensified regimen & $19(56)$ & $5(26)$ & 0.01 \\
\hline $\begin{array}{l}\text { Ordered identifiable } \\
\text { hypertension tests }\end{array}$ & $2(6)$ & $2(11)$ & 0.55 \\
\hline $\begin{array}{l}\text { Referred to hypertension } \\
\text { specialist }\end{array}$ & 0 & 0 & - \\
\hline $\begin{array}{l}\text { Overall appropriate } \\
\text { management }\end{array}$ & $19(56)$ & $6(32)$ & 0.02 \\
\hline $\begin{array}{l}\text { Among patients } \\
\text { nonadherent over entire } \\
\text { monitoring period or in } \\
\text { week prior to outcome } \\
\text { visit }\end{array}$ & $N=32$ & $N=18$ & \\
\hline $\begin{array}{l}\text { Documented addressing } \\
\text { adherence }\end{array}$ & $27(84)$ & $7(39)$ & 0.005 \\
\hline $\begin{array}{l}\text { Changed regimen to } \\
\text { improve adherence }\end{array}$ & $3(9)$ & $1(6)$ & 0.65 \\
\hline $\begin{array}{l}\text { Overall appropriate } \\
\text { management }\end{array}$ & $27(84)$ & 7 (39) & 0.005 \\
\hline Among all patients & $N=65$ & $N=35$ & \\
\hline $\begin{array}{l}\text { Overall appropriate } \\
\text { management }\end{array}$ & $45(69)$ & $12(34)$ & 0.001 \\
\hline
\end{tabular}

Data are presented as $N(\%)$ unless otherwise specified

The overall number of patients who received appropriate clinical action does not add up to the sum of the individual actions, as patients could have received more than one appropriate clinical actions

These results were consistent with several small studies assessing the impact of sharing objective measures of BP medication adherence with providers. ${ }^{4-46}$ In the study by Burnier et al., electronically monitoring patients with resistant hypertension was associated with reduced clinical inertia and improved BP control. This study, however, was limited by its small sample size $(N=41)$ and lack of control group. The study by Hyman et al. tested an intervention to reduce uncertainty about reasons for uncontrolled BP, and showed that their intervention reduced clinical inertia. Yet, in this study, electronic monitoring was optional and but one-part of a multi-

Table 4. Comparison of Patient-Rated Quality of Care and Clinician Communication According to Study Arm in the Measuring Adherence to Control Hypertension (MATCH) Trial

\begin{tabular}{llll}
\hline \hline Outcome measure & $\begin{array}{l}\text { Electronic } \\
\text { adherence } \\
\text { intervention } \\
(\boldsymbol{N}=\mathbf{6 5})\end{array}$ & $\begin{array}{l}\text { Usual care } \\
\text { control } \\
(\boldsymbol{N = 3 5 )}\end{array}$ & $\begin{array}{l}\boldsymbol{p} \\
\text { value }\end{array}$ \\
\hline $\begin{array}{l}\text { Patient-centered } \\
\text { communication about } \\
\text { hypertension }\end{array}$ & $38(59)$ & $13(37)$ & 0.001 \\
$\begin{array}{l}\text { Collaborative } \\
\text { communication about } \\
\text { hypertension }\end{array}$ & $32(49)$ & $10(29)$ & 0.02 \\
$\begin{array}{l}\text { Quality of care during } \\
\text { visit rated very good or } \\
\text { excellent (versus poor, } \\
\text { fair, or good) }\end{array}$ & $45(71)$ & $18(53)$ & 0.05 \\
$\begin{array}{l}\text { Just the right amount of } \\
\text { time for visit }\end{array}$ & $60(92)$ & $28(80)$ & 0.11 \\
\hline
\end{tabular}

Data are presented as $N(\%)$ unless otherwise specified. Data are missing from 3 participants for quality of care rating 
component intervention. Our study, in contrast, demonstrated that electronic monitoring feedback, alone, reduced clinical inertia. The trial by Santschi et al. most closely resembled our design in that they utilized a cluster randomized design to demonstrate that electronically monitoring adherence to a single BP medication was associated with increased medication titrations and better BP control. In this small trial $(N=65)$, however, their intervention was done in collaboration with pharmacists and appropriateness of clinical actions was not evaluated. We extended their findings by demonstrating that providing clinicians, alone, with an electronic adherence report not only reduced clinical inertia, but improved the appropriateness of clinical actions and patient-clinician communication.

There were several strengths of this study. First, few studies have sought to maximally reduce uncertainty about adherence by electronically measuring adherence to the near-complete antihypertensive regimen as opposed to a single medication. Second, the study was conducted in a socioeconomically vulnerable patient population with a large number of racial and ethnic minorities - a population often excluded from clinical trials.

The study also had several limitations. A substantial number of patients who underwent electronic monitoring were not included in the analyses due to non-compliance with electronic monitoring and lack of timely reports, and thus, the results likely represent an optimistic estimate of the effect of electronic monitoring in clinical inertia in practice. Electronic monitoring cannot confirm whether pillbox openings represent pill-taking behavior. Clinicians in the control group did not receive a report, and hence, one cannot determine the extent to which the intervention effect was due to a nonspecific prompt about adherence or to the receipt of the electronic adherence report. The intervention was only evaluated at a single patient visit; whether continuous electronic monitoring is needed to have a sustained impact on clinical inertia is worthy of further study. The trial was stopped early, and thus, even with the presence of a stopping rule, effect sizes should be interpreted cautiously. There were an unequal number of patients in the intervention and control groups, but this was attributable to the lack of balanced randomization at the patient level. The measure of adherence counseling has not been externally validated. A majority of patients had uncontrolled BP despite three or more BP medications, and patients were only eligible if they had persistently elevated BP even after adherence monitoring. Thus, the generalizability of our findings to other patient populations is unknown. The trial was not powered to detect differences in BP; a much larger number of patients is needed to test this outcome. Finally, electronic monitoring is not yet widely accessible in routine practice. Nevertheless, the advent of wireless adherence devices whose data can autopopulate electronic medical records may increase the feasibility of this approach in the future.

In summary, providing clinicians with electronic adherence data at the time of patient visits was an efficacious approach to increasing regimen intensification in adherent patients and increasing adherence counseling in nonadherent patients. Future studies should assess the impact of such an intervention on medication adherence and BP. Efforts to integrate electronic monitoring into clinical settings hold promise for improving patient-centered care and hypertension control in patients with uncontrolled hypertension.

Corresponding Author: Ian M. Kronish, M.D., M.P.H.; Center for Behavioral Cardiovascular HealthColumbia University Medical Center, 622 West 168th Street, PH9-311, New York, NY 10032, USA (e-mail: ik2293@cumc.columbia.edu).

\section{Compliance with Ethical Standards:}

Funding Sources: This project was funded by the NIH (K23 HL098359, UL1 TR000040) and the American Heart Association (SDG 2600321). Dr. Gallagher received support from NHLBI (T35 HL007616). Dr. Davidson received support from NHLBI (K24 HL084034). The sponsors had no role in the design and conduct of the study, nor in the collection, management, analysis, and interpretation of the data, nor in the preparation, review, approval of the manuscript, and decision to submit the manuscript for publication.

Conflict of Interest/Disclosures: The authors declare that they do not have a conflict of interest.

\section{REFERENCES}

1. Wolf-Maier K, Cooper RS, Banegas JR, Giampaoli S, Hense HW, Joffres M, Kastarinen M, Poulter N, Primatesta P, Rodriguez-Artalejo F, Stegmayr B, Thamm M, Tuomilehto J, Vanuzzo D, Vescio F. Hypertension prevalence and blood pressure levels in 6 European countries, Canada, and the United States. JAMA : J Am Med Assoc. 2003;289:2363-9.

2. Nwankwo T, Yoon SS, Burt V, Gu Q. Hypertension among adults in the United States: National Health and Nutrition Examination Survey, 20112012. NCHS data brief. 2013:1-8.

3. Ogden LG, He J, Lydick E, Whelton PK. Long-term absolute benefit of lowering blood pressure in hypertensive patients according to the JNC VI risk stratification. Hypertension. 2000;35:539-43.

4. Maronde RF, Chan LS, Larsen FJ, Strandberg LR, Laventurier MF, Sullivan SR. Underutilization of antihypertensive drugs and associated hospitalization. Med Care. 1989;27:1159-66.

5. Staessen JA, Fagard R, Thijs L, Celis H, Arabidze GG, Birkenhager WH, Bulpitt CJ, de Leeuw PW, Dollery CT, Fletcher AE, Forette F, Leonetti G, Nachev C, O'Brien ET, Rosenfeld J, Rodicio JL, Tuomilehto J, Zanchetti A. Randomised double-blind comparison of placebo and active treatment for older patients with isolated systolic hypertension. the Systolic Hypertension in Europe (Syst-Eur) Trial Investigators. Lancet. 1997;350:757-64.

6. Guo F, He D, Zhang W, Walton RG. Trends in prevalence, awareness, management, and control of hypertension among United States adults, 1999 to 2010. J Am Coll Cardiol. 2012;60:599-606.

7. Frieden TR, Berwick DM. The "Million Hearts" initiative-preventing heart attacks and strokes. N Engl J Med. 2011;365:e27.

8. Lloyd-Jones DM, Hong Y, Labarthe D, Mozaffarian D, Appel LJ, Van Horn L, Greenlund K, Daniels S, Nichol G, Tomaselli GF, Arnett DK, Fonarow GC, Ho PM, Lauer MS, Masoudi FA, Robertson RM, Roger V, Schwamm LH, Sorlie P, Yancy CW, Rosamond WD. Defining and setting national goals for cardiovascular health promotion and disease reduction: the American Heart Association's strategic Impact Goal through 2020 and beyond. Circulation. 2010;121:586-613.

9. Bramley TJ, Gerbino PP, Nightengale BS, Frech-Tamas F. Relationship of blood pressure control to adherence with antihypertensive monotherapy in 13 managed care organizations. J Manag Care Pharm. 2006;12:239-45.

10. Ho PM, Magid DJ, Shetterly SM, Olson KL, Peterson PN, Masoudi FA, Rumsfeld JS. Importance of therapy intensification and medication 
nonadherence for blood pressure control in patients with coronary disease. Arch Intern Med. 2008;168:271-6.

11. DiMatteo MR. Variations in patients' adherence to medical recommendations: a quantitative review of 50 years of research. Med Care. 2004;42:200-9.

12. Phillips LS, Branch WT, Cook CB, Doyle JP, El-Kebbi IM, Gallina DL, Miller CD, Ziemer DC, Barnes CS. Clinical inertia. Ann Intern Med. 2001;135:825-34

13. Ogedegbe G. Barriers to optimal hypertension control. J Clin Hypertens. 2008;10:644-6.

14. Oliveria SA, Lapuerta P, McCarthy BD, L'Italien GJ, Berlowitz DR, Asch SM. Physician-related barriers to the effective management of uncontrolled hypertension. Arch Intern Med. 2002;162:413-20.

15. Rose AJ, Shimada SL, Rothendler JA, Reisman JI, Glassman PA, Berlowitz DR, Kressin NR. The accuracy of clinician perceptions of "usual" blood pressure control. J Gen Intern Med. 2008;23:180-3.

16. Hyman DJ, Pavlik VN. Self-reported hypertension treatment practices among primary care physicians: blood pressure thresholds, drug choices, and the role of guidelines and evidence-based medicine. Arch Intern Med. 2000;160:2281-6.

17. Osterberg L, Blaschke T. Adherence to medication. N Engl $\mathrm{J}$ Med. 2005;353:487-97.

18. Chapman RH, Benner JS, Petrilla AA, Tierce JC, Collins SR, Battleman DS, Schwartz JS. Predictors of adherence with antihypertensive and lipidlowering therapy. Arch Intern Med. 2005; 165:1147-52.

19. Chobanian AV, Bakris GL, Black HR, Cushman WC, Green LA, Izzo JL Jr, Jones DW, Materson BJ, Oparil S, Wright JT Jr, Roccella EJ. The seventh report of the joint national committee on prevention, detection, evaluation, and treatment of high blood pressure: the JNC 7 report. JAMA : J Am Med Assoc. 2003;289:2560-72.

20. Ockene IS, Hayman LL, Pasternak RC, Schron E, Dunbar-Jacob J. Task force \#4-adherence issues and behavior changes: achieving a long-term solution. 33rd Bethesda Conference. J Am Coll Cardiol. 2002;40:630-40.

21. Miller NH, Hill M, Kottke T, Ockene IS. The multilevel compliance challenge: recommendations for a call to action. a statement for healthcare professionals. Circulation. 1997;95:1085-90.

22. Zeller A, Taegtmeyer A, Martina B, Battegay E, Tschudi P. Physicians' ability to predict patients' adherence to antihypertensive medication in primary care. Hypertens Res : Off $\mathrm{J}$ Japanese Soc Hypertens. 2008;31:1765-71

23. Turner BJ, Hecht FM. Improving on a coin toss to predict patient adherence to medications. Ann Intern Med. 2001;134:1004-6.

24. Cramer JA, Mattson RH, Prevey ML, Scheyer RD, Ouellette VL. How often is medication taken as prescribed? a novel assessment technique. JAMA : J Am Med Assoc. 1989;261:3273-7.

25. Choo PW, Rand CS, Inui TS, Lee ML, Cain E, Cordeiro-Breault M, Canning C, Platt R. Validation of patient reports, automated pharmacy records, and pill counts with electronic monitoring of adherence to antihypertensive therapy. Med Care. 1999;37:846-57.

26. Farmer KC. Methods for measuring and monitoring medication regimen adherence in clinical trials and clinical practice. Clin Ther. 1999;21:107490. discussion 1073

27. Hughes D. When drugs don't work: economic assessment of enhancing compliance with interventions supported by electronic monitoring devices. Pharmacoeconomics. 2007;25:621-35.

28. Chobanian A, Bakris G, Black H, Cushman W, Green L, Izzo J Jr, Jones D, Materson B, Oparil S, Wright J Jr. Seventh report of the Joint National Committee on prevention, detection, evaluation, and treatment of high blood pressure. Hypertension. 2003;42:1206.

29. Pickering TG, Hall JE, Appel LJ, Falkner BE, Graves J, Hill MN, Jones DW, Kurtz T, Sheps SG, Roccella EJ. Recommendations for blood pressure measurement in humans and experimental animals: part 1: blood pressure measurement in humans: a statement for professionals from the Subcommittee of Professional and Public Education of the American Heart Association Council on High Blood Pressure Research. Circulation. 2005;111:697-716.

30. Charlson ME, Pompei P, Ales KL, MacKenzie CR. A new method of classifying prognostic comorbidity in longitudinal studies: development and validation. J Chronic Dis. 1987;40:373-83.

31. Naik AD, Kallen MA, Walder A, Street RL Jr. Improving hypertension control in diabetes mellitus: the effects of collaborative and proactive health communication. Circulation. 2008;117:1361-8.

32. Glasgow RE, Wagner EH, Schaefer J, Mahoney LD, Reid RJ, Greene SM. Development and validation of the Patient Assessment of Chronic Illness Care (PACIC). Med Care. 2005;43:436-44.

33. Bultman DC, Svarstad BL. Effects of physician communication style on client medication beliefs and adherence with antidepressant treatment. Patient Educ Couns. 2000;40:173-85.

34. James PA, Oparil S, Carter BL, Cushman WC, Dennison-Himmelfarb C, Handler J, Lackland DT, LeFevre ML, Mackenzie TD, Ogedegbe $O$, Smith SC Jr, Svetkey LP, Taler SJ, Townsend RR, Wright JT Jr, Narva AS, Ortiz E. 2014 evidence-based guideline for the management of high blood pressure in adults: report from the panel members appointed to the Eighth Joint National Committee (JNC 8). JAMA : J Am Med Assoc. 2014;311:507-20.

35. Friedman LMDD. Fundamentals of clinical trials. 3rd ed. St. Louis: Mosby; 1996.

36. Machin DCM, Fayers P, Pinol A. Statistical tables for the design of clinical trials. Oxford: Blackwell; 1997.

37. Adams G, Gulliford MC, Ukoumunne OC, Eldridge S, Chinn S, Campbell MJ. Patterns of intra-cluster correlation from primary care research to inform study design and analysis. J Clin Epidemiol. 2004;57:785-94.

38. Campbell MK, Mollison J, Steen N, Grimshaw JM, Eccles M. Analysis of cluster randomized trials in primary care: a practical approach. Fam Pract. 2000; 17:192-6.

39. Bolen SD, Samuels TA, Yeh HC, Marinopoulos SS, McGuire M, Abuid M, Brancati FL. Failure to intensify antihypertensive treatment by primary care providers: a cohort study in adults with diabetes mellitus and hypertension. J Gen Intern Med. 2008;23:543-50.

40. Hicks PC, Westfall JM, Van Vorst RF, Bublitz Emsermann C, Dickinson LM, Pace W, Parnes B. Action or inaction? decision making in patients with diabetes and elevated blood pressure in primary care. Diabetes Care. 2006;29:2580-5.

41. Kerr EA, Zikmund-Fisher BJ, Klamerus ML, Subramanian U, Hogan MM, Hofer TP. The role of clinical uncertainty in treatment decisions for diabetic patients with uncontrolled blood pressure. Ann Intern Med. 2008;148:717-27.

42. Haybittle JL. Repeated assessment of results in clinical trials of cancer treatment. Br J Radiol. 1971:44:793-7.

43. Prodhan MLK, Wittes J. Statistical monitoring of clinical trials: a unified approach; 2006; New York.

44. Burnier M, Schneider MP, Chiolero A, Stubi CL, Brunner HR. Electronic compliance monitoring in resistant hypertension: the basis for rational therapeutic decisions. J Hypertens. 2001;19:335-41.

45. Hyman DJ, Pavlik VN, Greisinger AJ, Chan W, Bayona J, Mansyur C, Simms V, Pool J. Effect of a physician uncertainty reduction intervention on blood pressure in uncontrolled hypertensives-a cluster randomized trial. J Gen Intern Med. 2012;27:413-9.

46. Santschi V, Rodondi N, Bugnon O, Burnier M. Impact of electronic monitoring of drug adherence on blood pressure control in primary care: a cluster 12-month randomised controlled study. Europ J Internal Med. 2008; 19:427-34. 